\title{
TEKNIK HYPNO-BREASTFEEDING UNTUK KECUKUPAN ASI PADA IBU MENYUSUI
}

\author{
Bunga Tiara Carolin, Cholisah Suralaga, Ferdita Lestari \\ Program Studi Kebidanan, Fakultas Ilmu Kesehatan, Universitas Nasional Jakarta \\ Email Korespondensi: bunga.tiara@civitas.unas.ac.id
}

\begin{abstract}
ABSTRAK
World Health Organization (WHO) menetapkan target pemberian ASI pada bayi sekurang - kurangnya 50\% pada tahun 2025. Capaian ASI di dunia saat ini sebesar 36\%. Di indonesia (2019) cakupan ASI eksklusif masih 52,3\%, dibawah target nasional. Berdasarkan laporan formulir pencatatan ASI eksklusif di Puskesmas baros bulan September beberapa desa masih berada dibawah target yaitu tidak mencapai $45 \%$. Tujuan penelitian untuk mengetahui pengaruh teknik hypnobreastfeeding terhadap kecukupan ASI bayi pada ibu menyusui di wilayah kerja Puskesmas Baros. Metode: Penelitian menggunakan desain quasi experiment dengan one group pretest-postest design. Populasi adalah 30 ibu menyusui yang berada di wilayah kerja Puskesmas Baros. Teknik pengambilan sampel menggunakan metode systematic random sampling. Subjek penelitian sebanyak 15 responden yang memenuhi kriteria inklusi. Uji statistik yang digunakan adalah paired T-Test. Hasil Penelitian menunjukkan ada peningkatan signifikan kecukupan asi dengan p-value 0,000, berarti ada pengaruh pemberian teknik Hypno breastfeeding terhadap kecukupan ASI. Ada pengaruh pemberian teknik Hypno breastfeeding terhadap kecukupan ASI. Diharapkan tekhnik hypnobreastfeeding ini dapat menjadi solusi bagi ibu menyusui yang mengalami masalah pengeluaran ASI.
\end{abstract}

Kata kunci: ibu menyusui; kecukupan ASI; teknik hypno breastfeeding

\section{HYPNO-BREASTFEEDING TECHNIQUES ON ADEQUACY OF BREAST MILK AMONG BREASTFEEDING WOMEN}

\begin{abstract}
The World Health Organization has set a target of breastfeeding infants at least $50 \%$ by 2025. The achievement of breastfeeding in the world is currently $36 \%$. In Indonesia (2019), exclusive breastfeeding coverage is still 52.3\%, below the national target. Based on the report on the exclusive breastfeeding registration form at the Baros Health Center in September, several villages were still below the target, which was not reaching $45 \%$. The purpose of this study was to determine the effect of the hypno-breastfeeding technique on the adequacy of breast milk for baby on breastfeeding mothers at Baros District Health Center. The study used a quasi-experimental design with one group pretest-posttest design. The population was 30 breastfeeding mothers who are in the area the Baros District Health Center. The sampling technique used systematic random sampling method. The research subjects were 15 respondents who met the inclusion criteria. The statistical test used is the paired T-Test. The results showed that there was a significant increase in the adequacy of breastfeeding with a p-value of 0.000 , meaning that there is an effect of the Hypno-breastfeeding technique on the adequacy of breastfeeding. There is an effect of giving Hypno-breastfeeding technique to the adequacy of breast milk. It is hoped that this hypno-breastfeeding technique can be a solution for breastfeeding mothers who have problems with breastfeeding.
\end{abstract}

Keywords: breastfeeding mother; adequacy of breast milk; Hypno-breastfeeding Technique 


\section{LATAR BELAKANG}

World Health Organization menetapkan target pemberian ASI pada bayi sekurang kurangnya $50 \%$ pada tahun 2025. Capaian ASI di dunia saat ini sebesar $36 \%$ dan beberapa negara di Asia Tenggara seperti India sebesar 46\%, Philipina 34\%, dan Vietnam 17\% (World Health Organization, 2016). Di indonesia pada tahun 2019 cakupan ASI eksklusif masih dibawah target Nasional 80\% yaitu 52,3\%, kemudian di propinsi Banten $61,6 \%$ dan Kabupaten Lebak dengan 40,28 Atau masih dibawah target $45 \%$ (Dinas Kesehatan Provinsi Banten, 2019).

Air Susu Ibu (ASI) merupakan satusatunya makanan yang sempurna dan terbaik bagi bayi karena mengandung unsur-unsur gizi yang dibutuhkan oleh bayi untuk pertumbuhan dan perkembangan bayi guna mencapai pertumbuhan dan perkembangan bayi yang optimal. ASI adalah hadiah yang sangat berharga yang dapat diberikan kepada bayi, dalam keadaan miskin mungkin merupakan hadiah satu-satunya, dalam keadaan sakit mungkin merupakan hadiah yang menyelamatkan jiwanya (Dewi, 2013).

Berdasarkan data Riset Kesehatan Dasar tahun 2018 menunjukkan bahwa persentase pemberian ASI saja dalam 24 jam terakhir (ASI Ekslusif) semakin menurun seiring meningkatnya umur bayi dengan persentase terendah pada anak umur 6 bulan (30,2\%). Persentase nasional proses mulai menyusu pada anak umur 0-23 bulan, mulai menyusu kurang dari satu jam (IMD) setelah bayi lahir adalah $34,5 \%$, dengan persentase tertinggi di Nusa Tenggara Barat $(52,9 \%)$ dan terendah di Papua Barat (21,7\%), sementara provinsi Sumatera Utara 22,9\% (Kemenkes RI, 2018).

Alasan yang paling umum ibu memilih mengakhiri menyusui adalah bahwa susu "kering". Dan susah keluar akan tetapi, menurut beberapa penelitian, alasan - alasan yang tepat terkait dengan ini adalah stres, kecemasan, dan bekerja diluar rumah yang menyebabkan ASI sulit keluar sehingga ibu enggan menyusui dan memilih pengganti ASI untuk bayinya. Ibu menyusui yang cemas dan stres dapat menghambat pengeluaran ASI, karena pengeluaran ASI akan berlangsung baik dan lancar pada ibu yang merasa rileks dan nyaman. Selain itu rendahnya pemberian ASI eksklusif dipengaruhi beberapa faktor salah satu diantaranya adalah gencarnya promosi susu formula, ibu harus kembali bekerja, kurangnya kesadaran dan 3 pengetahuan ibu tentang pentingnya pemberian ASI dan manfaat ASI, serta harga susu formula yang ekonomis, merupakan faktor yang menyebabkan ibu enggan memberikan ASI pada bayinya.

Kenyataan di lapangan masih banyak ibu yang mengalami hambatan untuk menyusui bayinya secara eksklusif 6 bulan penuh, padahal menyusui merupakan suatu kondisi yang alamiah/natural. Mempersiapkan ibu hamil yang akan menyusui mempengaruhi keberhasilan menyusui. Salah satu solusi yang dapat membantu mengatasi hambatan dalam pemberian ASI eksklusif adalah teknik hypnobreastfeeding. Dengan teknik ini dapat meningkatkan produksi ASI sehingga bayi mendapatkan cukup ASI.

Dasar teknik hypnobreastfeeding adalah relaksasi yang dicapai bila jiwa raga berada dalam kondisi tenang. Adapun timbulnya suasana relaksasi dapat didukung oleh ruangan/suasana tenang, menggunakan musik untuk relaksasi, ditambah aroma therapy, panduan relaksasi otot, napas dan pikiran (Armini, 2016). Selain itu menurut penelitian lain menemukan adanya hubungan yang bermakna antara tenaga kesehatan terlatih dengan peranan tenaga kesehatan dalam mendukung pemberian ASI Eksklusif (Carolin \& Kholilah, 2019).

Produksi ASI dipengaruhi oleh hormon prolaktin dan oksitosin. Produksi kedua hormon ini sangat dipengaruhi oleh kondisi psikologis ibu dan hypnobreastfeeding ini mampu memberikan ketenangan pada ibu nifas. Semakin ibu tenang, percaya diri dalam memberikan ASI, dan yakin akan memberikan yang terbaik untuk bayinya maka hormon prolaktin dan oksitosin semakin banyak diproduksi (Diyan \& Asmuji, 2017).

Hasil penelitian Kusmiayati dan Wahyuningsih (2014) menunjukkan bahwa pada kelompok perlakuan yaitu kelompok yang mendapat hypnobreastfeeding ada penurunan 
tingkat kecemasan. Uji statistik menunjukkan adanya perbedaan yang bermakna, dengan taraf signifikan sebesar 0,00 sedangkan pada kelompok kontrol terjadi peningkatan kecemasan sedangkan pada kelompok perlakuan terjadi penurunan kecemasan. Hasil analisis independent $t$ test menunjukkan adanya perbedaan yang bermakna, hal ini dapat dilihat dari taraf signifikan sebesar 0,000. Tujuan penelitian ini adalah untuk mengetahui pengaruh teknik hypnobreastfeeding terhadap kecukupan ASI bayi pada ibu menyusui di wilayah kerja Puskesmas Baros Kecamatan Warunggunung Kabupaten Lebak Propinsi Banten Tahun 2021.

\section{METODE}

Penelitian ini menggunakan jenis penelitian quasy experiment dengan rancangan one group pretest-posttest design. Populasi dalam penelitian ini adalah ibu menyusui di wilayah kerja Puskesmas Baros Kecamatan Warunggunung Kabupaten Lebak, Banten yang berjumlah 30 orang. Teknik pengambilan sampel menggunakan total populasi. Kriteria inklusi pada penelitian ini yaitu bayi dengan ibu menyusui primipara 4-7 hari, ibu melahirkan secara normal (pervaginam), ibu dengan masalah pengeluaran ASI (Asi kurang), sedangkan kriteria eksklusinya yaitu ibu menyusui yang mempunyai penyakit infeksi herpes aktif di daerah vagina, infeksi saluran kemih, infeksi jamur, atau infeksi menular seksual (IMS), ibu menyusui multipara dan ibu melahirkan dengan section caesarea.

Alat ukur dalam penelitian ini menggunakan lembar observasi. Intervensi melakukan hipno breasfeeding 2x perhari (pagi dan sore) dengan durasi 15 menit selama 7 hari. Indikator yang digunakan untuk mengetahui kecukupan ASI pada penelitian ini berisi 10 pertanyaan dengan pilihan jawaban yang di ambil dari Dewi (2011). Setiap pertanyaan diberi nilai 10 bila jawaban "ya" dan bila jawaban "tidak" diberi nilai 0 . Pertanyaannya yaitu apakah bayi menyusu tiap 2-3 jam atau dalam 24 jam; apakah kotoran bayi berwarna kuning dengan frekuensi sering dan lebih mudah pada hari ke 5 setelah lahir; apakah bayi buang air kecil (BAK) paling tidak 6-8 kali sehari; ibu dapat mendengarkan pada saat bayi menelan ASI; ibu merasa payudara terasa lebih lembek, yang menandakan ASI telah habis; warna kulit bayi kemerahan, dan kulit terasa kenyal; pertumbuhan berat badan dan tinggi badan bayi sesuai dengan grafik pertumbuhan; perkembangan motorik (gerakan) bayi (bayi aktif dan motoriknya sesuai dengan rentang usianya); bayi terlihat puas, sewaktu saat lapar akan bangun dan tidur dengan cukup; bayi menyusu dengan kuat, kemudian melemah dan tertidur pulas. Kemudian hasilnya ditotal menggunakan score dengan kategori tidak cukup ( $\leq 55 \%)$, Kurang (56-75\%) dan Cukup (76-100\%). Berdasarkan hasil uji normalitas juga didapatkan bahwa data berdistribusi normal sehingga analisis data menggunakan paired t-test.

\section{HASIL}

Hasil penelitian pengaruh hypnobreastfeeding terhadap kecukupan ASI digambarkan dalam tabel berikut ini;

Tabel 1. Gambaran Kecukupan ASI

\begin{tabular}{ccccc}
\hline & Mean & S D & Min-max & $\begin{array}{c}\boldsymbol{P} \\
\text { value }\end{array}$ \\
\cline { 1 - 4 } Pre test & 62.67 & 8.837 & $50-70$ & 0.000 \\
\hline Post tes & 84.67 & 9.155 & $80-100$ & \\
\hline
\end{tabular}

Tabel 1 menunjukan distribusi frekuensi kecukupan ASI sebelum diberi terapi hypnobreastfeeding yaitu nilai mean 62,67 (ASI kurang) dengan standar deviasi 8,837. Sedangkan sesudah di beri terapi hypnobreastfeeding yaitu nilai mean 84,67 (ASI cukup) dengan standar deviasi 9,155. Berdasarkan uji paired $t$ test didapatkan $\mathrm{p}$ value 0,000 yang berarti bahwa hypnobreastfeeding berpengaruh terhadap kecukupan ASI.

\section{PEMBAHASAN}

Teknik hypno breastfeeding adalah upaya alami menanamkan niat kepikiran bawah sadar kita untuk menghasilkan ASI yang cukup untuk kepentingan bayi. Hal ini bisa diperoleh dengan memikirkan hal-hal positif 
yang dapat menimbulkan rasa kasih dan cinta kepada si bayi. Hypnobreastfeeding adalah metode yang sangat baik untuk membangun niat positif dan motivasi dalam menyusui.

Hypno breastfeeding adalah teknik relaksasi untuk membantu kelancaran proses menyusui, dengan memasukkan kalimatkalimat afirmasi positif ke dalam alam pikiran saat relaks atau dalam keadaan hipnosis. Kalimat afirmasi positif diharapkan mampu membantu proses menyusui. Relaksasi yang dalam dan teratur membuat sistem endokrin, aliran darah, persyarafan dan system lain di dalam tubuh akan berfungsi lebih baik. Menjaga sikap positif sangat penting selama menyusui. Karena rileks saat menyusui menyebabkan hormone endorphin yang diproduksi ibu akan mengalir ke bayi melaluiASI, dan membuat ba,vijuga merasakan kenyamanan dan ketenangan (Kusmiyati \& Wahyuningsih, 2014).

Relaksasi memunculkan perasaan tenang, nyaman dan bahagia yang akhirnya dapat meningkatkan hormon prolaktin dan oksitosin untuk kelancaran produksi ASI. Keadaan relaksasi juga akan mengaktifkan pikiran bawah sadar ibu sehingga ibu akan dengan mudah terpengaruh oleh sugesti positif yang akan meningkatkan keyakinan ibu dalam proses menyusui. Keyakinan atau kepercayaan diri ibu akan kecukupan produksi ASInya dapat meningkatkan atau mempertahankan produksi ASI ibu. Terapi hypnobreastfeeding dilakukan dengan menggunakan teknik relaksasi untuk mengurangi kecemasan dan stres ibu sehingga dapat meningkatkan produksi ASI. Cara ini dilakukan dengan menyisipkan kalimat afirmasi positif yang membantu ibu menyusui saat dalam keadaan rileks. Makanya, pola pikir ibu akan dibuat lebih positif dan percaya diri (Kusmiyati \& Wahyuningsih, 2014),(Anuhgera et al., 2017).

Studi lain menunjukkan bahwa Hypnobreastfeeding secara statistik maupun secara klinik memiliki pengaruh bermakna terhadap keberhasilan pemberian ASI Eksklusif dengan nilai $p<0,05$. Efek yang ditimbulkan sebesar 3,11 kali lebih besar dibandingkan dengan tanpa hypnobreast- feeding. Koefisien determinan sebesar 0,07 menunjukkan bahwa hypnobreastfeeding diprediksi memengaruhi keberhasilan pemberian ASI Eksklusif sebesar $7 \%\left(R^{2}=0\right.$, 07) (Nuratri et al., 2015).

Laily et al (2021) mengatakan pada penelitinnya Sebelum diberikan edukasi melalui terapi hypnobreastfeeding, hanya 33,3\% ibu yang memiliki sikap baik tentang pemberian ASI eksklusif pada anak. Setelah dilakukan intervensi selama 2 bulan persentase peningkatan sikap baik sebanyak 73,3\% (Laily et al., 2021).

Hasil penelitian ini juga sejalan dengan penelitian lain bahwa terdapat pengaruh hypnobreastfeeding terhadap kecukupan ASI pada bayi di Puskesmas Kahuripan Kecamatan Tawang Kota Tasikmalaya, terbukti dengan tingkat signifikansi ( $\rho$ value) 0,020.(Napilah et al., 2018). Hasil penelitian ini sejalan dengan penelitian Armini (2016) menunjukkan bahwa responden selalu datang rutin untuk mendapatkan teknik hypnobreastfeeding. Teknik ini jika dilakukan secara teratur, akan menimbulkan bonding dan selanjutnya memicu tubuh untuk menghasilkan hormon endorfin (hormon pembawa rasa senang dan tenang) sehingga tubuh merasa rileks (Armini, 2016).

Penelitian Rahmawati dan Prayogi (2017) juga mengatakan Rata-rata produksi ASI sebelum hypnobreast-feeding setiap hari mengalami fluktuatif yang tidak menentu sedangkan setelah hypnobreastfeeding terjadi peningkatan secara konstan (Rahmawati \& Prayogi, 2017).

Menurut asumsi peneliti, adanya pengaruh teknik hypnobreastfeeding terhadap kelancaran produksi ASI. Hal tersebut dapat dibuktikan pada ibu yang diberi pertanyaan 10 indikator tentang kelancar ASI sebelum dilakukan hypnobreastfeeding mendapatkan skor $\geq 50 \%$ yang artinya tidak cukup dan setelah diberikan hypnobreastfeeding selama 15 menit ibu di beri pertanyaan kembali tentang kelancaran ASI mendapatkan skor 80\%-100\% yang artinya cukup. Teknik hypnobreastfeeding merupakan salah satu upaya untuk memperlancar produksi ASI dan dapat berhasil jika ibu memiliki keinginan yang kuat 
serta ketaatan ibu untuk melakukan teknik hypnobreast-feeding. Sebelum menyusui, ibu harus dalam keadaan tenang tidak stress maka akan terjadi ikatan antara ibu dan bayi sehingga dapat memperlancar produksi ASI. Kelemahan dalam penelitian ini penilaian kecukupan asi hanya menggunakan kuesioner yang dijawab oleh ibu, sehingga bersifat subjektif serta penelitian ini tidak mengkaji faktor-faktor yang mempengaruhi kecukupan ASI.

\section{KESIMPULAN DAN SARAN}

Ada peningkatan kecukupan ASI pada ibu menyusui setelah diberikan hypobreastfeeding. Diharapkan ibu hendaknya memiliki kesadaran dan pengetahuan yang baik tentang ASI eksklusif dengan cara menggali informasi dari petugas kesehatan atau membaca majalah sehingga ibu dapat memberikan ASI eksklusifnya dengan baik dan benar untuk mencapai tingkat kesehatan bayi yang optimal. Bila terjadi masalah dalam pengeluaran ASI terutama pada ibu primipara di hari-hari pertama melahirkan maka tekhnik hypnobreastfeeding ini dapat menjadi solusi dalam pengeluaran ASI. Saran untuk peneliti selanjutnya agar dilakukan penilaian produksi ASI secara objektif.

\section{REFERENSI}

Anuhgera, D. E., Kuncoro, T., Sumarni, S., Mardiyono, M., \& Suwondo, A. (2017). Effect of Combination of Hypnobreastfeeding and Acupressure on Anxiety and Wound Pain in Post-Caesarean Mothers. Belitung Nursing Journal, 3(5), 525-532. https://doi.org/10.33546/bnj.191

Armini, N. W. (2016). Hypnobreastfeeding Awali Suksesnya ASI Eksklusif. Jurnal Skala Husada, 1, 21-29.

http://download.garuda.ristekdikti.go.id/article.php ?article=808447\&val=13183\&title=Hypnobreastfee ding, Starting Exclusive Breastfeeding To Be Success
Carolin, B. T., \& Kholilah. (2019). Faktor-Faktor Yang Berhubungan Dengan Peranan Tenaga Kesehatan Terhadap Dukungan Pemberian Asi Eksklusif Di Rumah Sakit M Jakarta Selatan. Jakhkj, 5(1), 9-21.

Dewi, M. U. K. (2013). Efektivitas Gentle Birth Terhadap Pemberian ASI Eksklusif. Jurnal IImiah Kebidanan, 4(505), 150-156.

Dinas Kesehatan Provinsi Banten. (2019). Profil Dinas Kesehatan Provinsi Banten 2019. In Dinas Kesehatan Provinsi Banten.

Diyan, I., \& Asmuji. (2017). In Postpartum ' S Mother Work And Do Not Work In Sumbersari Jember Puskesmas Area. Jurnal Penelitian IPTEKS, 2(2), 148-153.

Kemenkes RI. (2018). Riset Kesehatan Dasar (RISKESDAS).https://doi.org/10.1088/17518113/44/8/085201

Kusmiyati, Y., \& Wahyuningsih, heni P. (2014). Pengaruh Hypnobreastfeeding Terhadap Kecemasan dan Waktu Pengeluaran Air Susu Ibu pada Ibu Post Partum Primipara di Yogyakarta. Journal Teknologi Kesehatan, 10(2), 123-127.

Laily, N., Rahman, F., Putri, A. O., Noor, M. S., Rahayu, A., Yulidasari, F., Anggraini, L., Anhar, V. Y., Sari, A. R., Rosadi, D., Afifah, A., Azmiannoor, M., \& Bohari, B. (2021). Implementation of hypnobreastfeeding therapy as an effort to reduce the incidence of underweight on children aged 0-6 months. Open Access Macedonian Journal of Medical Sciences, 9(E), 123-126. https://doi.org/10.3889/ oamjms.2021.5686

Napilah, I. S., Herliani, Y., \& Astiriyani, E. (2018). Pengaruh Hypnobreastfeeding Pada Ibu Hamil Trimester lii Terhadap Kecukupan Asi Pada Bayi Di Puskesmas Kahuripan Kecamatan Tawang Kota Tasikmalaya Tahun 2018. Jurnal Sehat Masada, XII(2), 85-93. https://doi.org/10.48186/bidkes.v2i9.86

Nuratri, C. A. E., Dasuki, D., \& Wibowo, T. (2015). Untuk Keberhasilan Pemberian Asi Eksklusif Di Rs X Yogyakarta. STIKES Santo Borromeus, 33, 5561.

Rahmawati, A., \& Prayogi, B. (2017). Hypnobreastfeeding untuk Meningkatkan Produksi ASI pada Ibu Menyusui yang Bekerja. Seminar Nasional Dan Gelar Produk, 48-53.

World Health Organization. (2016). Pencatatan dan Pelaporan Cakupan ASI Eksklusif. 